\title{
Cultivation of Network Ecological Civilization Consciousness of College Students
}

\author{
Chundi Lan*, Haixia He \\ School of Marxism, Jiangxi Normal University, Jiangxi Nanchang,330022, China \\ *aLancd2013@jxnu.edu.cn
}

\begin{abstract}
The cultivation of college students' network ecological civilization consciousness is to cultivate college students' positive network ecological security consciousness, civilized network participation consciousness, noble network moral consciousness, good network legal consciousness and good network behavior habit. Cultivating college students' awareness of network ecological civilization is conducive to the formation of good Internet habits, physical and mental health, network power and the realization of the goal of beautiful China. However, there are some problems in the cultivation of college students' network ecological civilization consciousness, such as the shortage of network ecological civilization environment and the insufficient integration of network ecological civilization education into classroom education. Therefore, it is necessary to strengthen college students' self-education, build a scientific and universal network ecological civilization awareness education system and create a good network ecological environment.
\end{abstract}

Keywords: College students; Network ecological civilization; awareness.

\section{Introduction}

Marx said, "Man is the product of nature, developed in and with his own environment."With the development of information technology, the living environment of human beings is no longer a single real life environment, but also an online virtual environment. The Fourth Plenary Session of the 19th Central Committee of the Communist Party stressed that it should "establish and improve the network comprehensive governance system, strengthen and innovate the construction of network content, implement the subject responsibility of the Internet enterprise information management, comprehensively improve the network governance capacity and create a clear network space [1]". At present, due to the lack of correct understanding and use of the network, cyberspace has become a miasma, resulting in a series of problems. The most effective way to deal with the problems caused by the development of network society should be to cultivate the consciousness of network ecological civilization of the main body of the network. As an important participant in the network society, college students should have a high degree of consciousness of network ecological civilization, practice the concept of network ecological civilization, and standardize their own behavior in the network.

\section{The Significance of the Cultivation of College Students' Network Ecological Civilization.}

College students' awareness of network ecological civilization refers to the consciousness that college students have to protect the network ecological environment, make rational use of network information resources and get along well with other network subjects when carrying out network communication. The cultivation of network ecological civilization consciousness of college students is to carry out network ecological civilization education to college students in a purposeful, planned and organized way, so that students can master the basic theoretical knowledge of network ecological civilization; improve their network security consciousness, network participation consciousness, network moral consciousness, and network legal consciousness; promote them to form correct network ecological civilization consciousness; abide by the laws and regulations in network society; and practice the concept of network ecological civilization. This is of great significance for college students to form good Internet habits, ensure physical and mental health, and realize the goal of network power and beautiful China. 
First of all, cultivating college students' awareness of network ecological civilization is conducive to the formation of good Internet habits. College students are important participants and constructors in the network society. Whether they can use the network effectively and reasonably has become a necessary quality and ability of the current college students. At present, college students use the Internet frequently, not only the need of school online courses, but also the need of self-access to information and online entertainment. Because of curriculum tension, self-greed, partner instigation or other factors, uncivilized behavior appears when college students use the Internet, forming a bad habit of surfing the Internet. For example, college students surf the Internet frequently, but lack the relevant networksecurity awareness, register multiple software without recognization, random release their own personal information; some college students casually forward or comment the information they obtained without identification, resulting in certain network security risks. In order to make college students correct these bad Internet habits and form good Internet habits, it is necessary to improve the awareness of network security of college students, abide by the legal norms of the network, correctly identify the network information and form a good habit of surfing the Internet under the guidance of Marxist ecological civilization view and new development concept, through scientific, universal and organized education of network ecological civilization consciousness.

Secondly, the cultivation of college students' awareness of network ecological civilization is beneficial to the physical and mental health of college students. General Secretary Jinping Xi pointed out "many people, especially young people, obtained the most information from the Internet instead of scanning the mainstream media, we must pay attention to this fact[2]." The network environment faced by college students in the critical growth period can be described as strange and complex. Threre are all kinds of endless platforms, good and bad APP, conveying a lot of entertainment, funny, vulgar, and even ulterior motives, so as to attract many college students to relax their vigilance, easily accept or participate directly. In addition, the increased online games is easy for students to indulge in it, which makes them neglect learning and surf on the Internet endlessly. College students use the network for a long time, resulting in low back pain, vision loss, blurred consciousness and other health problems. By cultivating the network ecological civilization consciousness of college students, the college students can master the relevant theoretical achievements, strengthen the network legal consciousness, network moral consciousness and network participation consciousness, control the Internet time, avoid indulging in the network, and thus promote the development of college students' physical and mental health.

Finally, cultivating college students' awareness of network ecological civilization is conducive to the implementation of the goal of network power and beautiful China. General Secretary Jinping Xi said that "we should proceed from the international and domestic trends, overall layout, coordinate all parties, innovate development, and strive to build our country into a network power [3]". "The idea of building a network power includes five aspects: network innovation, network security, network talents, network space governance, and network destiny community [4]." The 18th National Congress of the Communist Party of China proposed that to build a beautiful China, the construction of ecological civilization must be put in a prominent position, and the network ecological civilization is the extension of the real ecological civilization in cyberspace, so the goal of beautiful China includes the ecological civilization construction of the network society. Therefore, to build a strong network and a beautiful China, we must build a network ecological civilization. "Youth rejuvenates the country, young people are strong, the country is strong, the young generation has the ideal, the ability, the responsibility, the country has the future, the nation has the hope [5]." As the new youth of the new era, college students must master the knowledge of network ecological civilization, put it into action, form good habits of surfing the Internet, take the initiative to participate in the governance of cyberspace, achieve the mutual benefit and harmonious symbiosis of people and network resources, network environment, and contribute to the realization of the goals of network power and beautiful China. 


\section{Problems Existing in the Cultivation of College Students' Consciousness of Network Ecological Civilization}

According to the 42nd Statistical report on the Development of Internet in China, till June 2018, the number of Internet users in China had reached 802 million, an increase of $3.8 \%$ over the end of 2017, and the Internet penetration rate had reached 57.7\% [6]. Among these netizens, college students account for a large proportion. College students have special psychological characteristics and behavior. Their thoughts are active and they can accept new things quickly. Their network life is colorful and the content of the Internet is complex and changeable. Thus, there are still many problems in the process of cultivating the consciousness of network ecological civilization.

\subsection{The College Students' Network Ecological Environment is to be Improved}

With the comprehensive promotion of $4 \mathrm{G}$ network, the research and development of $5 \mathrm{G}$ network and the continuous development of campus network, the network life of college students becomes more colorful. At the same time, they will also face complex network ecological environment, all kinds of platforms emerge in endlessly, they not only enrich students' life, but also affect their way of thinking and behavior, low threshold and immature network market rules, and so on, it makes the content of network society complex, college students often participate in it, make uncivilized network behavior, and even move towards crime. At present, the network ecological environment faced by college students generally has the following problems:

First, college students' network life environment is complex. At the beginning, the on-line environment is complex. The continuous updating of the mobile Internet terminal equipment, the virtual nature of the network society and the like make the network environment complex, the content is complicated, the common network-based violence, the network pornography, the network rumor, "Some people regard the internet as a garbage bin for their own; Some people regard the public space of the internet as an extra-judicial place to search for human flesh and personal attacks [7]." Then the offline realistic environment needs to be improved. The improvement of the network ecological environment not only includes the online virtual environment, but also the offline real environment, because the network society partly reflects the real society. At present, the real living environment of college students also needs to be improved. It is said that the university campus is a small society, although the main body of the campus is students and teachers, but there is no lack of other personnel to enter, especially in the university that campus facilities continue to improve, in the campus social people can be seen everywhere. On the doors of some restrooms, you can even see malicious online classes, selling CET4 or CET6 answers, online pornographic websites and other information. It can be seen that the living environment of students is complex. Students are vulnerable to its influence, and produces uncivilized online behavior.

Second, campus network supervision is not enough. In the real life, China has strict control over the media, and the phenomenon of non-civilization in the society is less. In the network society, because of the openness and the virtual nature of the network society, the possibility of using the network to spread the unhealthy information by the network is increased; some people will use the anonymity of the network to attack the system of our country and even make anti-human speech; The hot issues of some society have been hyped up, the rumors of the network are made up, and people are confused. The contemporary college students who are in the long-term youth have a lot of disadvantages, and it is easy to generate many uncivilized phenomena in the internet. For example, on-line behavior and present implementation In order to deviate, there is a typical "behind the Internet celebrity"; lack of the ability to distinguish right from wrong, especially vulnerable to the impact of negative information on the Internet, and so on. Due to the lack of systematic network management and the complexity of the network environment, it is difficult for college students to monitor and correct their words and deeds in the network, which aggravates the confusion of the network society to a certain extent. Colleges and universities cannot monitor this in time, make correct decisions, guide network public opinion according to the situation, to some extent contribute to the development trend of dangerous speech and behavior. 


\subsection{The Integration of College Students' Network Ecological Civilization Education into Classroom Education is not Enough.}

Classroom teaching is the most direct official channel for college students to master the content of network ecological civilization, and the cultivation of college students' network ecological civilization needs to be closely combined with the classroom teaching to achieve the best results. At present, the university network ecological civilization education cannot be well integrated into the classroom teaching, the students' understanding of the network ecological civilization is still in the autonomous learning stage, the relevant knowledge cannot be learned from the official channel, the efforts to integrate the network ecological civilization education into the classroom education are to be strengthened.

First, the education of network ecological civilization consciousness is lack of science. In some western developed countries, they not only offer the course of network behavior norm education, but also integrate moral education into the teaching work. In our country, the education of network ecological civilization consciousness is not a compulsory course at present, and it is not popularized at present. When colleges and universities carry out the education of network basic skills course, they often only pay attention to the teaching of basic technology, but ignore the moral guidance to students. "some schools pay attention to the systematization and training of a few related specialties, but ignore the publicity of most other specialties; even if some schools have set up teaching courses, the formalization in teaching activities and superficial expression in practical activities frequently appear [8]", some colleges and universities even hold some image education activities only on some important anniversaries, among which there are few courses that really propagate the knowledge of network ecological civilization. After the school makes students master certain network technology through classroom education, if there is no correct moral guidance, the influence of his mistakes will be even worse. Therefore, colleges and universities need to integrate some knowledge of network ecological civilization in the classroom to cultivate college students' awareness of network ecological civilization.

Second, the education of network ecological civilization consciousness is lack of universality and practicality. The so-called universality means that the education of network ecological civilization consciousness is oriented to all college students, not to one major or one grade student, it is one of the various courses in colleges and universities, which can be related to other courses, and the cultivation of network ecological civilization consciousness can be integrated into classroom education, so that it can become a kind of universal education; The so-called practicality, that is, network ecological practice, "it mainly refers to the practical activities based on the law of the change and development of network ecology, taking the reasonable needs of netizens as the driving force, and aiming at the harmonious integration of people and network ecological environment[9]". At present, The network ecological civilization education for students in universities generally relies on ideological and political theory courses, depends on teachers' personal network literacy and the degree of mastery of related knowledge, and has little combination with students' professional courses, and does not regard the education of network ecological civilization consciousness as a kind of normal teaching work, the measurement of students' awareness level of network ecological civilization is only limited to the examination, lack of combination with practice, students are not willing to take the initiative to participate in the practice of network ecological civilization, the education of network ecological civilization awareness is still lack of universality and practicality.

\section{Countermeasures for Cultivating College Students' Consciousness of Network Ecological Civilization}

The virtualization and informatization of the network society enables the student to express his own viewpoint arbitrarily, the university student's network accomplishment is not high, the school to the network environment construction is not perfect and so on have increased the difficulty to the university student network ecology civilization consciousness cultivation. In order to cultivate college students' network ecological civilization consciousness, we should aim at the problems in the process 
of cultivation, combine the actual situation, find countermeasures, improve the cognition level of college students' network ecological civilization, cultivate college students' network ecological civilization consciousness and emotion, strengthen college students' recognition of network ecological civilization, and promote the construction of network ecological civilization.

\subsection{Strengthen the Self-education of College Students.}

In order to make college students have the consciousness of network ecological civilization, the most basic thing is to let college students carry out self-education, actively master the concept of network ecological civilization, and realize the important role of network ecological civilization, so that students can construct a higher awareness of network ecological civilization and turn it into a good network behavior. When cultivating the network ecological civilization consciousness of college students, we should make great efforts to improve their network literacy, gradually let them construct the network ecological civilization consciousness, let the students identify with the network ecological civilization ideologically, and consciously standardize their own network behavior.

First, guide college students to consciously self-discipline and introspect. Network society is a more complex living space than the real society. The information in the network is complicated and difficult to distinguish between truth and falsehood, which is undoubtedly dangerous for some people who lack self-discipline and self-reflection. Self-discipline is to enable college students to restrain themselves and abide by the rules and regulations of the network society when there is no supervision of others; consciousness is to require students to take the initiative to study the knowledge of network ecological civilization, and to be able to consciously restrain their online habits according to their requirements; introspect, Xunzi said that "the gentleman is knowledgeable and self-communion many times every day, then he will get smart and there are no mistakes in doing things", so as to cultivate the ecological civilization consciousness of college students, it is necessary to guide college students to reflect on themselves and reflect on whether their behavior is reasonable and legal.

Second, improve the self-education ability of college students. Improving the self-education ability of college students is an important way to cultivate the consciousness of network ecological civilization. Educators should fully respect the main role of students in the process of cultivation, give appropriate guidance according to the different ideological characteristics of students, give full play to their subjective initiative, and make college students educate themselves. Educators can adopt different methods in the process of cultivation, change the past one-way teaching mode, stimulate students' enthusiasm for learning, and can adopt two methods: individual education and collective education. Collective education can take the form of organizing collective discussions, watching role models film and television works, competitions and so on. Individual education can allow students to evaluate their own network behavior, sum up, and gradually change uncivilized behavior. Only by improving the ability of self-education, forming a good consciousness of network ecological civilization and placing themselves in the network ecological environment, can college students realize the value of individuals in the network, improve their practical ability of network ecological civilization, and strive tirelessly for the goal of network power.

\subsection{Create a Good Network Ecological Environment}

The influence of network environment on college students' network life and the construction of ideological and political theory courses in colleges and universities is expanding day by day. When cultivating college students' consciousness of network ecological civilization, we should attach great importance to the construction of network social environment, provide students with a good network environment, and speed up the formation of college students' consciousness of network ecological civilization.

First, strengthen network supervision and optimize the network environment. In order to strengthen network supervision and improve Internet conditions, we must increase the investment in hardware facilities at the beginning. It is necessary to let the network cover the whole campus, improve the network supervision technology, and timely monitor the intrusion of bad information. Then, it is necessary to strengthen the system construction, monitor some garbage and even harmful 
information in time, intercept effectively, set up network firewall, and protect students' Internet security. Finally, to increase the investment in technology, we can cooperate with the relevant colleges or departments of computer science and technology, increase the investment of professional and technical personnel, prohibit access to bad websites, and create a good network ecological environment for students. The construction of electronic reading room in colleges and universities and the utilization of micromedia are all measures for colleges and universities to create a good Internet environment for students.

Second, construct campus websites and propagandize mainstream culture. In the era of rapid development of the network, each university should have its own fixed website, but also have some platforms to promote campus culture, on these platforms, some healthy and harmonious, positive culture should be publicized. In cultivating college students' awareness of network ecological civilization, we should not only make good use of these websites, but also construct them. "To build the mainstream public opinion pattern of integration and under the Internet, internal and external publicity linkage, and to establish an all-media communication system based on content construction, supported by advanced technology and guaranteed by innovative management." It is necessary to increase investment in manpower and material resources, open up some more effective and attractive websites for ideological and political education with innovative thinking, strive to build websites that students like, publicize mainstream cultures such as socialist core values, and carry forward positive social energy. It can also make use of some intuitive videos, applications or cartoons to integrate campus resources to form a new situation of cultivating network ecological civilization consciousness, so that students can actively study, actively discuss, consciously practice and enhance the cultivation effect in a free, humorous and harmonious atmosphere.

\subsection{Establishing a Perfect Education System of Network Ecological Civilization Consciousness}

The perfect education system of network ecological civilization consciousness should carry out scientific and universal education of network ecological civilization consciousness, so that students can realize the two-way development of network ecological civilization cognition level and practice level, which is the inevitable requirement for the cultivation of college students' network ecological civilization consciousness.

First, optimize the curriculum construction of network ecological civilization education. In order to carry out scientific and universal education of network ecological civilization consciousness, it is necessary to optimize the curriculum of cultivating network ecological civilization consciousness, to integrate the cultivation of network ecological civilization consciousness into classroom teaching, to improve the scientific and universality of network ecological civilization education, to enable college students to grasp the relevant theoretical knowledge of network ecological civilization consciousness in an all-round way, deepen the understanding of network morality and network law and network security, and to be able to distinguish right from wrong, use the network correctly. In order to integrate the education of network ecological civilization consciousness into the teaching process, we should first regard the education of network ecological civilization consciousness as a universal education, increase its proportion in the public basic courses, systematically carry on the network ecological civilization education to the college students, and improve the college students' network ecological civilization consciousness. Then, using a variety of modern educational means, combine the network ecological civilization awareness education and the characteristics of different majors to form a knowledge docking, using Weibo, WeChat and other modern means, so that students can not only access the Internet, but also receive the network ecological civilization awareness education, and constantly improve their network behavior level. Finally, it is necessary to strengthen the construction of teachers. Teachers play an important role in the cultivation of college students' network ecological civilization consciousness, their network ecological civilization consciousness, the level of network literacy and network skills is directly related to the effect of cultivation. Therefore, "teachers need to make full use of teaching media and means to give full play to teachers' guiding role and teachers should be trained regularly [10]", strengthen the study of knowledge related to network ecological 
civilization, master modern network technology, improve their own network literacy, and enhance the educational effect.

Second, set up the practice platform of the network ecological civilization consciousness cultivation. The pure theory is that the church has pushed the cultivation of the network ecological civilization consciousness to the formalization and nothingness, so it is necessary to acquire the real and reliable knowledge of the network ecological civilization through the practice, and constantly promote the construction of the network ecological civilization. The network ecological civilization consciousness education is to be combined with the campus culture activities and the social practice activities of the university students, so that the students can truly feel the necessity of the network ecological civilization construction in practice, thus comparing the cognition and the behavior of the students and continuously improving. Set up the network ecological civilization awareness education practice platform, and let the students participate in the network ecological civilization awareness education practice platform, and knowledge and existing network literacy can be used to promote the overall development of college students. The construction of the practice platform of the network ecological civilization consciousness cultivation should adopt different forms according to the different situations of the university, the most convenient form is to use the community activities to organize some online ecological civilization exhibitions or lectures, etc., and provide the necessary explanation for the students involved in the activities, it is also possible to use the advantages of associations, groups and departments to organize various kinds of practical activities, for example, it is possible to take advantage of the "Network National Security Publicity Week" to organize a variety of activities to help the college students improve the legal literacy of the network and effectively guarantee the college students self-security, so as to achieve self-development, promote the construction of network ecological civilization.

\section{Summary}

The continuous development of network information technology and the continuous updating of mobile terminal equipment not only bring convenience to college students in life and study, but also make them fall into one dilemma after another, and even go to crime. In such an information age, in order to promote the development of network society, colleges and universities must attach importance to cultivating the awareness of network ecological civilization of college students, through strengthening the self-education of college students, perfecting the cultivation system of network ecological civilization consciousness, creating a good network ecological environment, so that college students can consciously run through the concept of network ecological civilization in practice, and constantly improve the cognitive level and practical level of network ecological civilization. Let college students be active in taking charge devoted to the practice of network ecological civilization construction.

\section{Acknowledgements}

Fund projects:2017 Project of the Research Center of Jinping Xi's thought of Socialism with Chinese characteristics in the New era of Jiangxi normal University:"A study on Jinping Xi's thought of Fairness and Justice in Socialism with Chinese characteristics in the New era", China Post-Doctoral Science Fund the 66th Surface Support Program, The Humanities and Social Sciences Project of Colleges and Universities in Jiangxi Province in 2017: Research on production Justice from the Perspective of Ecological Civilization (ZX17202).

\section{References}

[1]. Decisions of the CPC Central Committee on adhering to and perfecting the Socialist system with Chinese characteristics and promoting the Modernization of the National Governance system and Governance ability [EB/OL]. the Xinhua News Agency, 31th October, 2019. 
[2]. Jinping Xi. An excerpt from Jinping Xi's discussion on the Construction of Socialist Culture[M]. Beijing: Central Literature Publishing House, 2017:105-106.

[3]. Jinping Xi. Speech at the opening ceremony of the second World Internet Congress[N]. People's Daily, $17^{\text {th }}$ December, 2015.

[4]. Jianhua Cheng, Gang Wang. A study on Jinping Xi's Strategic thought of Network Power in the New era[J]. Journal of Guangdong University of Foreign languages and Foreign Trade, 2019, 30(03): 97-102.

[5]. Jinping Xi: Winning the well-off Society in an all-round way and winning the Great Victory of Socialism with Chinese characteristics in the New era-a report at the 19th National Congress of the Communist Party of China[R]. Beijing, People's Publishing House, 18th October 2017: 70.

[6]. China Internet Network Information Center. 42nd Statistical report on the Development of China's Internet[R/OL]. 20 ${ }^{\text {th }}$ Auguest, 2018. http://www.cac.gov.cn/2018-08/ 20/c_ 112329688 2.htm.

[7]. Xianliang Ren. The Network Society also needs "the Beauty of order"[N]. Guangming Daily, $20^{\text {th }}$ Auguest, 2015(002).

[8]. Jianfeng Li, Qiubo Yu, Xiurong Liu, Shuli Zhang. Ecological Responsibility of College Students from the Perspective of Ecological Civilization[J]. Impart knowledge and educate people (Higher education forum), 2018.

[9]. Xinlan Wang, Liming Luo. Network ecological personality: The Age Appeal of the Construction of the Network's Ecological Civilization[J]. Theoretical guide, 2017, (09).

[10]. Wei Feng, Qian Peng. A probe into the necessity and implementation Mechanism of Ecological Civilization quality Education for College students[J]. Higher education forum, 2018. 